\title{
Needed: A systems approach to improve flood risk mitigation through private precautionary measures
}

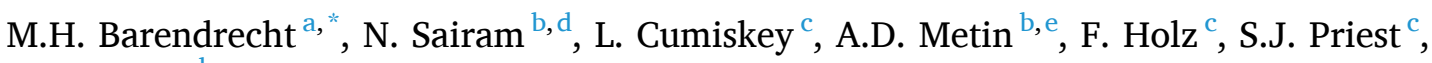 \\ H. Kreibich ${ }^{\text {b }}$ \\ ${ }^{a}$ Centre for Water Resource Systems, Vienna University of Technology, Vienna A-1040, Austria \\ ${ }^{\mathrm{b}}$ GFZ German Research Centre for Geosciences, Section Hydrology, Telegrafenberg, Potsdam 14473, Germany \\ ${ }^{\mathrm{c}}$ Flood Hazard Research Centre, Middlesex University, The Burroughs, London, UK \\ d Geography Department, Humboldt University, 10099 Berlin, Germany \\ ${ }^{\mathrm{e}}$ Institute of Earth and Environmental Science, University of Potsdam, 14476 Potsdam, Germany
}

\section{A R T I C L E I N F O}

\section{Keywords:}

Private precautionary measures

Systems approach

Flood risk management

\begin{abstract}
A B S T R A C T
Private precautionary measures play an increasingly important role in flood risk management. The degree to which private precautionary measures mitigate flood risk depends mainly on the type of measure (and how effective it is) and how frequently and successfully it is implemented. These aspects are influenced by a complex interaction of physical and socio-economic processes, which makes the assessment and the prediction of the mitigation of flood risk via private precautionary measures a challenge. This paper provides an overview of factors and processes that influence the implementation and effectiveness of private precaution in mitigating flood risk, underpinning it with highlights from international examples. We recommend private precautionary measures for further use to improve flood risk mitigation, but stress that they need to be considered and implemented through a holistic systems approach to maximize their effectiveness.
\end{abstract}

\section{Introduction}

In recent decades, there has been an increasing awareness of the need to shift flood risk management towards more integrated and adaptive strategies $[8,38]$. One aspect of integrated flood risk management is the fact that it takes into account that flood defenses might fail and thus it is important to complement flood protection with non-structural solutions $[38,40]$. Therefore, there has been an increasing recognition of the need to shift the focus of flood risk management from flood protection, e.g. through structural measures, to reducing the consequences of flooding, e.g. through reducing vulnerability of communities [33,45,6,50,24,14].

In order to reduce societies' vulnerability to flooding, there has been an increasing focus on private precautionary measures as a viable method for flood risk mitigation. Private precautionary measures are those measures undertaken at the property level to mitigate flood loss to contents and building structures, for example the use of water barriers [38]. There are different types of private precautionary measures. They may reduce flood loss by, for example, preventing water from entering the property; by making structural changes to the building; through avoiding expensive fittings on the lower levels, or may take the form of planning which actions to take in case of a flood event, such as moving valuables to a higher floor [34]. Private precautionary measures commonly implemented in Germany, for example, include "flood adapted use", "flood adapted interior fitting", "adapted building structure" and "flood barriers" [34]. In other literature, private precautionary measures may be called "property level resilience measures" [14], "property level flood risk adaptation" [32], "property-level flood protection" [50], "repairable measures", "flood resilience", "wetproofing" [15] or "resistance measures" [13]. In essence, they all describe similar types of measures, so for consistency the term "private precautionary measures" or "private precaution" will be used throughout the paper. In some cases, flood insurance is considered as a private precautionary measure (e.g. [7]). However, while other private precautionary measures have the aim to reduce loss, insurance only transfers the risk. Therefore, in this paper, flood insurance is not considered as a private precautionary measure, but instead as a factor that may influence the implementation of precautionary measures.

Studies have shown that private precaution can reduce loss $[37,26,53,56]$, but implementation/uptake levels are often low and usually only rise following a flood event $[36,18,32,50]$. Knowledge

\footnotetext{
* Corresponding author.

E-mail address: barendrecht@hydro.tuwien.ac.at (M.H. Barendrecht).
} 
about private precautionary measures and how to incorporate them into a flood risk management plan is scarce [38]. Recent literature has provided more insight into public behavior in terms of private precautionary measures (see Everett and Lamond [18] and Hanger et al. [21] for an overview) but a comprehensive synthesis of how private precaution works within the flood risk system is lacking.

The aim of this paper is to provide a scientific overview of internal and external factors and processes within the flood risk system that influence the implementation and effectiveness of private precaution in mitigating flood risk. This overview is underpinned with some highlights from international examples based on qualitative and quantitative research. We recommend private precautionary measures for further use to improve flood risk mitigation but stress that they need to be considered and implemented through a systems-approach to maximize their effectiveness. Implementing a systems approach requires considering all the processes and interactions of the flood risk system. Hence, one should consider flood risk reduction strategies through a comprehensive assessment of the effects and effectiveness of all types of measures together (e.g. structural measures, emergency measures, precautionary measures) instead of considering each measure on an individual basis. Interactions and feedbacks between these measures and the rest of the system may cause the overall effectiveness of these strategies to be different than the effectiveness of individual strategies on their own.

The remainder of this paper is structured as follows: we first discuss the complexity of the flood risk system and the need for considering the system as a whole, then we discuss private precaution from a governance perspective and finally we discuss the uptake and effectiveness of private precautionary measures. We conclude with a set of recommendations for a systems approach to improving flood risk mitigation through precautionary measures.

\section{Complexity of the flood risk systems}

There has been an increasing awareness of the necessity to shift the focus of flood risk management from managing the hazard to also include the management of exposure and vulnerability. However, research that investigates and quantifies the impact of various factors (e. g. land use change, flood insurance, private precaution) and their interactions on flood risk is still scarce. Fig. 1 shows flood risk with its three components and examples of the individual factors that may influence this risk. The diagram reflects the importance of considering flood risk management through private precaution from a systems perspective. The different components of flood risk, i.e. hazard, exposure and vulnerability, are influenced by factors that are both internal and external to the flood risk system. Hazard, for example, is influenced by climate change (external factor) and by flood risk management measures such as structural protection (internal factor). External factors such as culture may influence flood risk exposure or vulnerability, but can also influence the flood risk governance approach. The different components of the flood risk system and their interactions are discussed in this and the next section along with the three examples shown in Fig. 1 (example $a$ and $b$ in this section and example $c$ in the next section). The factors and examples shown in the diagram and discussed in this paper are not exhaustive, nevertheless, they serve as examples to illustrate the importance of taking a systems perspective.

To detect the impact of the different factors on flood risk change, approaches that are based on empirical loss data have been implemented in the past, such as loss normalization studies $[29,4,48,65]$ or data-based approaches (e.g. [6,34]). Although these approaches have provided a better understanding of changes in flood risk, it is hard to determine the influence of the individual factors on risk change. Normalization studies, for example, show that trends in losses (i.e. risk) are not influenced by the effect of human-induced climate change (e.g. [2]). However, the effect of climate change may be undetected because it is likely to be mitigated by adaptation measures, such as improved early warning systems, strengthened flood protection, or better private precaution $[17,20,31,44,46]$. Simulation-based approaches have the advantage of being able to estimate the contributions of different drivers through scenario runs. However, many of the simulation-based studies only consider changes in hazard and exposure. Changes in vulnerability, e.g. because of private precaution, are often neglected [46]. This is mainly due to a lack of data and knowledge about changes in vulnerability and the effects on flood risk [44,39].

Metin et al. [46] used a system-of-systems model (a model-system that couples detailed individual models that describe different processes, e.g. atmospheric, catchment and river processes or damage mechanisms), to quantify the sensitivity of flood risk to changes in the different risk systems, considering all components of the systems. They

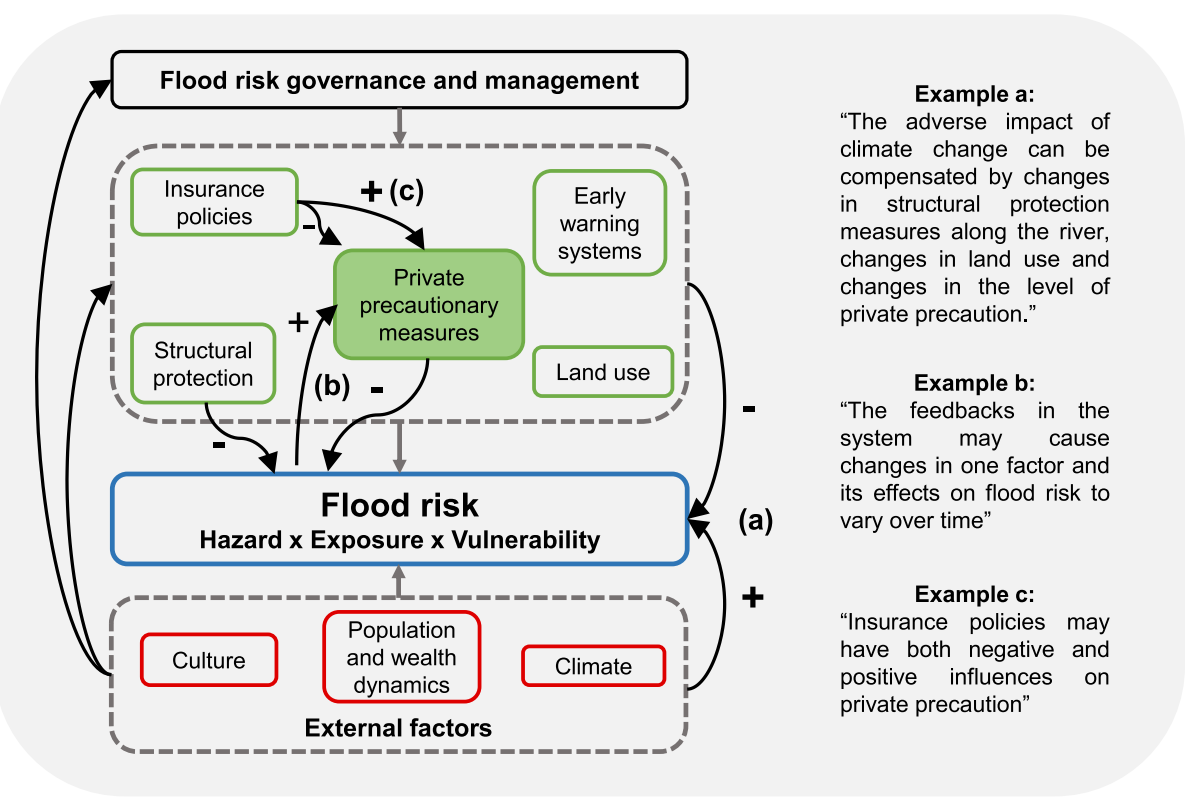

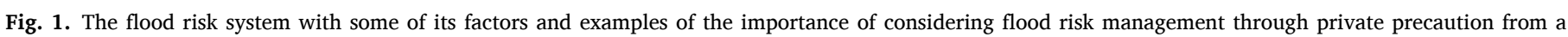

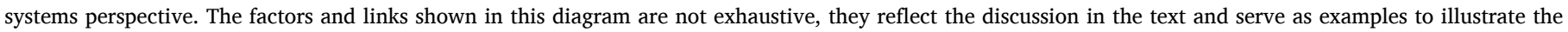
importance of a systems perspective. 
find that in the Mulde catchment in Germany, at the catchment scale, flood risk is most sensitive to changes in structural flood protection. The second largest contribution to flood risk comes from changes in land use, asset values and vulnerability (i.e. private precaution). The study also shows that the adverse impacts of climate change can be compensated by changes in structural protection measures along the river, changes in land use and changes in the level of private precaution. Example (a) in Fig. 1 illustrates how the impact of different factors on flood risk should be considered simultaneously, since the impact of one factor may be masked or influenced by another factor.

When comparing the feasibility of the different measures (i.e. dike heightening, land use change and private precaution), the best strategy to compensate the effects of climate change, would be to increase the uptake of private precaution [46]. These findings are specific to the example of the Mulde catchment and in another setting, private precaution may not be able to compensate for increases in risk that are caused by other factors (e.g. climate change). The study by Metin et al. [46] shows that private precaution can be effective in decreasing flood risk and that for a comprehensive assessment it is important to simultaneously consider all the factors that are defining flood risk.

While the study by Metin et al. [46] does take into account private precaution and its effects on flood risk, the authors do not consider changes in the different factors over time. Barendrecht et al. [1] use a conceptual model to show that in Dresden preparedness (i.e. the uptake of private precautionary measures) has varied temporally and therefore its influence on loss or flood risk changes as well. These changes over time are the result of feedbacks in the system: due to a natural period without floods, people's awareness reduces (i.e. they forget about the risk) and therefore the uptake of private precautionary measures is low. This caused the flood related loss in 2002 to be higher than it could have been if more measures were implemented. In 2013, when awareness and the uptake of precautionary measures had increased due to the experience of the 2002 event, loss was much lower, even though the event was similar in magnitude to the event in 2002. This can also occur due to a "non-natural" period without flooding, which occurs when structural protection measures are implemented. On the contrary, if people are used to regular flooding, an adaptation effect may occur and they may be better prepared to deal with it [1]. Example (b) in Fig. 1 illustrates the importance of considering feedbacks between the different factors of the system. It shows that changes in one of the factors that influences risk (e. g. the construction of structural protection) with the intention to reduce risk can have negative consequences and influences other factors, which may eventually increase flood risk. Changes in structural protection may also influence the uptake of private precaution in a more direct way. In a study on the implementation of private precautionary measures in the Italian Alps, Scolobig et al. [57] find that trust in structural protection may be a reason for individuals not to increase their preparedness, even though they are aware of the risk. Bradford et al. [5] found that respondents in Ireland were not aware of the flood risk despite having experienced flooding before. This lack of awareness was caused by the fact that respondents were living next to structural protection that was constructed after they experienced flooding. The implementation of new structural flood defenses can also influence the existing adaptation and ability to mitigate flood risk of a society. Hazarika et al. [23] contend that the people in the Upper Brahmaputra plain had adapted to the local flood situation by, for example, raising their houses and adapting agricultural practices. However, when the government implemented new flood control measures, which did not completely stop flooding from occurring but rather changed the nature of the flooding, the people were less able to cope with this new type of flooding, because their agricultural practices were not adapted to it.

These examples show that it is important to consider private precaution from a systems perspective (e.g. considering all the processes and interactions of the flood risk system) when studying its effects on flood risk as well aswhen considering the implementation of risk reduction measures. Intended or unintended consequences of actions need to be identified within the system in order to fully appreciate whether any flood risk management intervention will have a positive effect on reducing flood risk.

\section{Flood risk governance and private precaution}

Although there is a general tendency to move towards diversification in flood risk management, countries are struggling with implementation [24]. The uptake of precautionary measures remains low, in part, because governments are dealing with challenges that hinder the implementation of private precautionary measures. For example, consideration of private precaution needs to occur at different phases of flood risk management (e.g. preparedness, response and recovery). Responsibilities also lie across different sectors (e.g. construction industry, planning, insurance, flood risk), government levels (national, regional, local) or with individual homeowners. Precautionary measures can be self-initiated by homeowners and/or directed or incentivized by government initiatives which adds additional governance complexity around implementation, including roles and responsibilities and any associated liabilities [16].

In England, individuals are increasingly encouraged to take personal responsibility for managing their own flood risk [30]. Correspondingly, in Germany, the German Federal Water Resource Act states that every person who is at risk of flooding has the obligation to take appropriate action [55] thereby initiating private precaution. A key challenge, however, is that households and businesses may still feel that it is the responsibility of the authorities to manage flood risk, usually in the form of structural measures (e.g. [50]) thereby inhibiting their interest in selfprotection. In Canada, Henstra et al. [25] found that 55\% of the public feels that homeowners are responsible for flood risk mitigation but the amount that respondents would be willing to pay for private precautionary measures would not be enough to reduce flood risk. This highlights another problem that arises with the shift of responsibilities towards the individual: the question of who should fund private measures and arguments of elitism (e.g. only the richest being able to afford measures) if the burden falls solely upon individual homeowners [51]. Furthermore, technical implementation issues for private precautionary measures arise when there are interdependences between properties. In order to be effective some precautionary measures will need to be implemented (and operated) for multiple properties [15]. Jointdecision-making, financing and co-implementation in these situations can make the adoption of private precautionary measures considerably more challenging.

To encourage the implementation of private precautionary measures, governments may provide funding directly to affected households through post-event recovery grants (e.g. English Property Level Flood Resilience Grant Scheme, [12,32]. In England, the government also proactively (ex-ante) funds private precautionary measures to manage property flood risk in particular situations, such as when it is not viable to implement structural measures [43]. In Germany and many other countries, such initiatives are absent and individuals are expected to privately fund their own precautionary measures $[55,61]$. Where government funding initiatives do exist these can help households overcome some of the financial barriers, although these initiatives still can have poor uptake [62]. The decision and motivation of households to invest in private precaution depends on multiple factors (as will be discussed in more detail in section 4). Households, for instance, may be constrained by their knowledge of the range and effectiveness of different measures, which can be enhanced if there are local flood groups or demonstration houses, like the Cumbria Resilience Showcase [16].

The availability of incentives such as reduced insurance premiums or continued availability of insurance could also influence individuals' interest in personally financed uptake, as shown by Poussin et al. [52] for France. However, the lack of knowledge on the effectiveness of private precautionary measures hinders insurers' interest in funding them [27]. The insurance sector in the United Kingdom is working 
towards a 'flood performance certificate' that can be attached to a household to act as an incentive for reduced premiums [60]. On the other hand, insurance may also negatively influence the uptake of precautionary measures, when households realise they will be compensated, thus reducing uptake motivation $[30,21]$. Thus, insurance policies can influence private precaution both positively and negatively which demonstrates the need for a systems approach. Example (c) in Fig. 1 highlights the importance of considering the implementation of flood insurance schemes from a systems perspective, because of the unintended consequences it may have on private precaution.

Another governance challenge is the associated liability when private precautionary measures do not function as expected, as well as concerns about standards and product warranty. The availability and quality of precautionary measures is driven entirely by the private market and thus product design, construction quality and standards of implementation may vary. This challenge was highlighted by a local flood authority representative in England:

"It's a bit of a nasty beast because there are lots of commercial organisations. We've had enquiries from people that got the grant and then the stuff has failed and then there is nothing they can do about it so then they come to us thinking that we go back to the original problem." (Local Authority interviewee, England)

Some guidelines and quality standards exist, for example the Flood Resilient Building Guidance for Queensland Homes [59]. However, there is a lack of consistency across the market and concerns about the selling of inappropriate and ineffective products $[15,16]$ for associated flood hazard types (see also section 4). In an attempt to control this, in the United Kingdom, for example, a "Code of Practice and guidance for property flood resilience" is being developed and a new British Standard for flood products will replace an older one [16]. However, the degree to which these are followed by developers, contractors and suppliers is unclear.

Private precautionary measures can act as a valuable addition alongside other flood risk management measures to reduce the residual risk and therefore reduce losses for extreme events. The identified governance challenges highlight the complexity of effectively implementing private precautionary measures. As the examples show, the actions of multiple actors (product suppliers, insurers, homeowners and governments) are interlinked and influence the uptake and effectiveness of precautionary measures. This warrants the need for a systems approach which recognizes the complex governance challenges of implementation.

\section{Private precaution: Motivation for uptake and effectiveness}

The effect of private precaution on flood risk depends on the uptake of measures, i.e. whether people are motivated to adopt measures and whether they actually implement them, as well as on the effectiveness of the measures in mitigating loss. In this section, we discuss the factors of the flood risk system influencing the willingness to take measures (motivation for uptake)and the loss-reducing effectiveness of private precautionary measures. Fig. 2 focuses on these two aspects of private precaution and the factors influencing them.

\subsection{The motivation for the uptake of private precautionary measures}

According to protection motivation theory there are two important aspects that influence the motivation for the uptake of precautionary measures by private properties: threat appraisal and coping appraisal [6] (see also Fig. 2). Threat appraisal relates to the awareness of being at risk and to whether a threat is perceived. This is influenced by factors such as: flood experience, personal characteristics, and risk communication. Several studies observe that the experience of flood loss is positively correlated with the uptake of precautionary measures $[7,49,35,50,52,5,66]$. However, even though the experience of a flood may increase the awareness of being at risk, this can be undermined by authorities' actions or poor communication of the uncertainties and probabilities $[3,41]$. An example of this occurred in Cumbria, where after the flood event in 2009 threat appraisal became very low. The authorities were speaking of an exceptional event that would not happen very often, therefore the residents and businesses felt safe behind the existing flood protection that they were told had a design period of 1 in

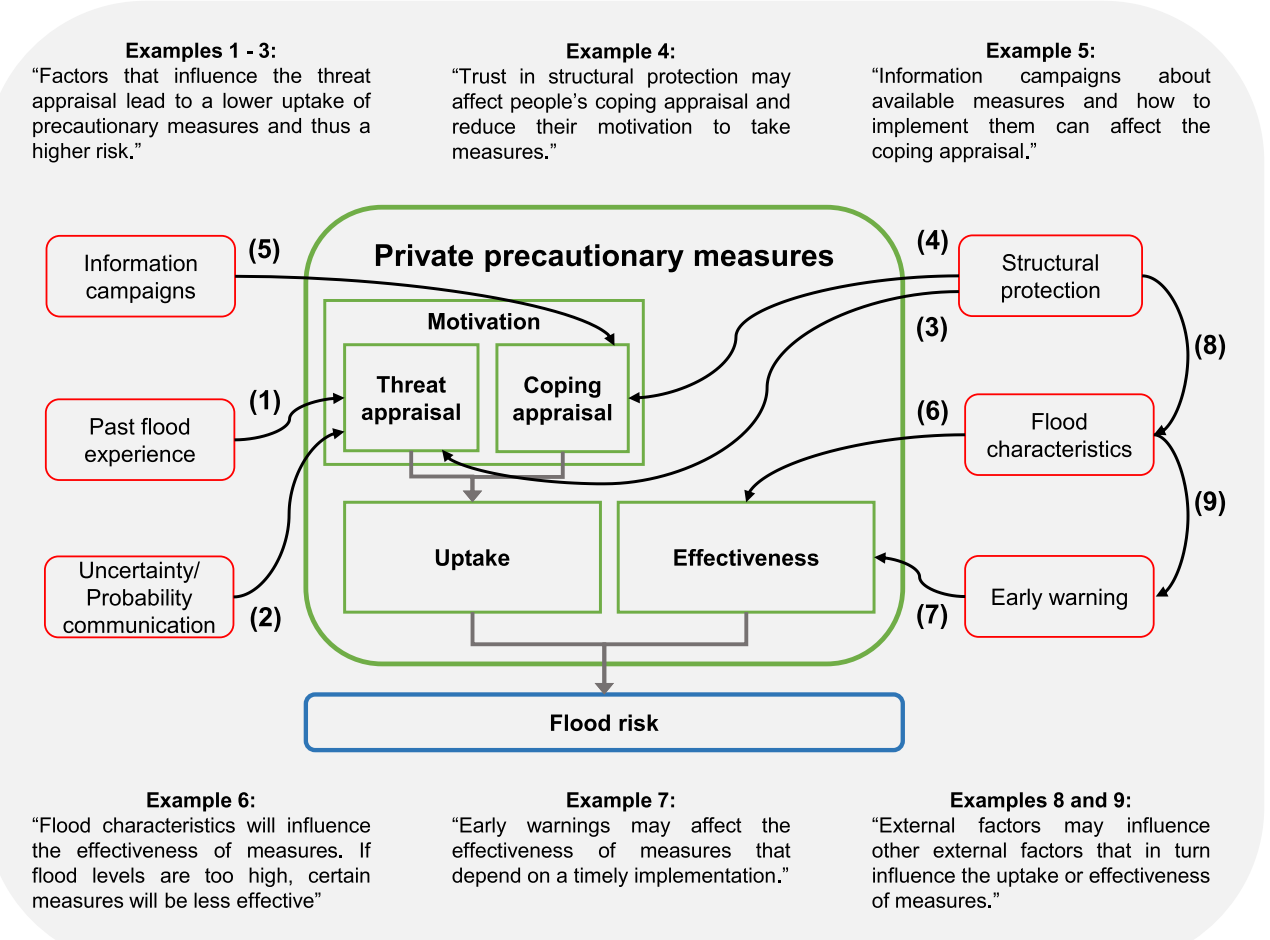

Fig. 2. The aspects of private precaution and flood risk management factors influencing them. 
100 years and were surprised to be flooded again as soon as 2015 [67]. A business owner that was affected by the floods in 2009 and 2015, indicated they were surprised that a second flood occurred again so soon:

"We were totally sure that it would never happen again. they said it was a one in a hundred year flood or something. And they built defences, so we were pretty confident that it wouldn't happen again. We had thoughts in mind of what we would do, but we didn't, we honestly didn't expect it to flood again, so rather naive I guess." (Business owner, England)

Examples (1), (2) and (3) in Fig. 2, illustrate that while factors like experience may have a positive influence on threat appraisal and thus on the uptake of measures, this positive influence may be canceled in combination with other factors like a poor communication about flood probabilities and the implementation of structural measures.

The second factor, coping appraisal is a measure of how well people are able to cope with a threat. It depends on the perceived self-efficacy, response efficacy and response costs [6]. There may be different ways of coping with a threatening situation that do not all result in an increase in the uptake of precautionary measures or adaptation [7]. This can include factors such as worry $[47,54]$ or trust in structural protection $[58,67]$. For example, Hanger et al. [21] found that respondents in Austria and England that are protected by public structural measures are less likely to take private precautionary measures. Example (4) in Fig. 2 highlights the influence of other flood risk management measures like the construction of structural protection may have an unintended effect on coping appraisal. Another reason for people not to implement measures is anxiety that this may influence future house prices, because it identifies the property as being at risk of flooding [9].

Coping appraisal also depends on whether people have the knowledge and resources to implement measures. Several studies have shown that it is important to include information about the specific measures themselves and their benefits as a part of risk communication in order to increase the uptake of measures [19,7]. In Appleby (England), for example, people were willing to implement measures, but did not know which measures to implement. A pilot project that provided funding for surveys and measures helped people to choose the correct measures and increased the uptake of private precaution [22]. A study in Canada highlights the importance of considering the difference between the general intention to implement private precautionary measures and the willingness to implement individual measures [58]. The former is more influenced by fear and risk perception, while the latter instead depends more on the perceived response efficacy and costs [58]. Example (5) in Fig. 2 highlights the importance of providing adequate information about measures and how to implement them to increase people's coping appraisal.

\subsection{The effectiveness of private precautionary measures}

The effect of private precautionary measures in reducing flood losses to building structures was found to be non-marginal. In Germany, the loss prevented by implementing private precautionary measures was estimated to be between $€ 11,000$ and $€ 15,000$ per household, per event [56]. This accounts for $27 \%$ of the average incurred damages to household buildings in Germany during the flood events between 2002 and 2013. Hudson et al. [26] estimated that individual measures such as flood adapted use or flood adapted interior fitting reduce damages to household building structures in Germany by $€ 14,385$ and $€ 11,302$ and damage to household contents by $€ 6,732$ and $€ 5,202$, respectively. Research in the United Kingdom has shown that measures can reduce damages by $50-100 \%$ [63]. In France, Poussin et al. [53] find that precautionary measures may reduce building and contents damages by up to $€ 6,500$. The most effective measure was elevating the ground floor, which costs $€ 25,000-69,000$ to implement for existing buildings and $€ 1900-9800$ for new buildings [53].

Poussin et al. [53] also found that the effectiveness of the different measures depends on the characteristics of the flooding (i.e. slow onset river flooding, or rapid flash/coastal flooding), as well as on the closeness of the building to the source of the flooding. Also, the frequency of flooding strongly influences the cost-efficiency of private precautionary measures. Therefore, it is important to identify appropriate measures for each type of building and flood risk. In Carlisle, for example, flood gates would not have contributed much to reducing the loss of the 2015 event, because water levels were too high (Cumbria County [10]. In this case other measures might have been more appropriate, such as using a coating for walls, or replacing wooden with brick or concrete floors. Example (6) in Fig. 2 shows the importance of choosing the appropriate measures for the location of interest, because the effectiveness of the measures depends on location specific characteristics of both floods and buildings.

Cumiskey et al. [11] categorized measures into active (requiring implementation just before/during the event: e.g. flood barriers) and passive measures (which do not require implementation: e.g. sealing the basement). The effectiveness of private precaution in reducing flood loss depends on the quality of installation and timely uptake (for active measures) of the appropriate measure. This shows again, that it is important to consider the effectiveness from a systems perspective, since it may interact with or be influenced by other factors. For example, the presence of early warning systems and whether they function properly, will affect the effectiveness of active measures, since the implementation of those measures depends on residents being aware of an approaching flood in a timely manner [11]. Example (7) in Fig. 2 illustrated how the implementation of other flood risk management measures like early warning systems may affect the effectiveness of private precautionary measures that require people to take actions at the onset of a flood event.

Since the frequency of flooding has been shown to determine whether private precaution is cost-efficient [53], this means that other flood management measures that reduce the frequency of flooding, such as building structural protection, would reduce the cost-efficiency of private precautionary measures. Climate change may also cause flood characteristics to change, which may influence the technical effectiveness of private precautionary measures, since it depends on flooding type and characteristics. The effectiveness of early warning also depends on flooding type and characteristics. Slow onset flooding happens slowly and usually gives people time to prepare, in the case of flash floods however, there is usually not enough time to provide a timely warning. Examples (8) and (9) in Fig. 2 highlight how the different factors that influence the effectiveness of private precaution may also affect each other. Structural protection may change flood characteristics, which not only directly changes the effectiveness of measures but may in turn also affect early warning systems.

\section{Conclusion}

We argue that private precautionary measures can help to mitigate flood risk and should not be underestimated as part of a flood risk management strategy, especially with climate change putting increasing pressure on existing risk management strategies. However, private precaution can only be effectively implemented if it is considered from a holistic systems perspective. The strength of the role of precautionary measures depends on many interrelated aspects within the risk management system which may reduce or strengthen its effectiveness. Up to now, both research and flood risk management have been focusing mostly on individual aspects.

We propose several strategies for adopting a systems approach, concerning the aspects of flood risk data, modelling and governance. It is crucial to increase our understanding of the systems and interactions using a comprehensive documentation of past events encompassing hydrological aspects, structural protection failures, early warning, private precautionary measures implemented as well as losses that occurred. In addition to these event-specific data, information on changes in several aspects of flood risk management that occurred between different flood events can improve the understanding of the 
system as a whole as well as the effect of different components. This information is especially valuable to understand the impact of variations in government policies and behavior of individuals and communities influencing the implementation and effectiveness of planned and implemented measures.

A number of modelling approaches may be implemented in combination with findings from empirical data to understand the drivers of flood risk, their interactions and feedbacks, and to quantify the influence of their combined effect on the entire system. The modelling approach that is adopted, depends on the assumptions, the level of complexity and the system components. This includes, but is not limited to, conceptual models or system-of-systems models. These models potentially combine all or at least multiple aspects of the flood risk system, their interactions and feedbacks. Though many of these models are theoretical, it is very important that they depict the reality of the system and are useful for practitioners. Therefore, we strongly recommend rigorous evaluation of these models using empirical data.

Implementing private precaution effectively requires collective action across multiple actors, including the public and private sectors, insurance companies and product suppliers, local and national governments, individuals and homeowners. Further research is needed to understand the governance challenges and the most appropriate governance mechanisms (e.g. legal regulations, partnerships, funding schemes) to enable stronger coordination across these actors and encourage uptake of private precaution. Furthermore, a better understanding is needed on the role of private precaution within the landscape of other flood risk management measures, and how the balance between different measures could evolve over time, as more extreme and frequent flood events are expected.

While this review focuses on the use of private precautionary measures as part of a flood risk management strategy, the recommendation to use a systems approach applies to the risk management of any natural hazard, not only floods. Similarly to managing flood risk, private precautionary measures also play an important role in the risk management of wildfires, hurricanes or earthquakes and their effectiveness and implementation is influenced by many factors $[42,64,28]$. In the future, an even more holistic systems approach may include considering multihazard risk.

\section{Declaration of Competing Interest}

The authors declare that they have no known competing financial interests or personal relationships that could have appeared to influence the work reported in this paper.

\section{Acknowledgements}

We would like to thank two anonymous reviewers and the editor for their useful comments to the original version of the paper. We would like to acknowledge funding from the Marie Sklodowska-Curie Innovative Training Network "A Large-Scale Systems Approach to Flood Risk Assessment and Management-SYSTEM-RISK" (grant agreement 676027)); and the FWF Vienna Doctoral Programme on Water Resource Systems (W1219-N22).

\section{References}

[1] M.H. Barendrecht, A. Viglione, H. Kreibich, B. Merz, S. Vorogushyn, G. Blöschl, The value of empirical data for estimating the parameters of a sociohydrological flood risk model, Water Resour. Res. (2019).

[2] J.I. Barredo, Normalised flood losses in Europe: 1970-2006, Nat. Hazards Earth Syst. Sci. 9 (1) (2009) 97-104.

[3] H.M. Bell, G.A. Tobin, Efficient and effective? The 100-year flood in the communication and perception of flood risk, Environ. Hazards 7 (4) (2007) 302-311.

[4] L.M. Bouwer, Have disaster losses increased due to anthropogenic climate change? Bull. Am. Meteorol. Soc. 92 (1) (2011) 39-46.
[5] R.A. Bradford, J.J. O'sullivan, I.M. Van der Craats, J. Krywkow, P. Rotko, J. Aaltonen, ... K. Schelfaut, Risk perception-issues for flood management in Europe, Nat. Hazards Earth Syst. Sci 12(7) (2012) 2299-2309.

[6] P. Bubeck, W.J.W. Botzen, H. Kreibich, J.C.J.H. Aerts, Long-term development and effectiveness of private flood mitigation measures: an analysis for the German part of the river Rhine, 2012.

[7] P. Bubeck, W.J. Botzen, H. Kreibich, J.C. Aerts, Detailed insights into the influence of flood-coping appraisals on mitigation behaviour, Global Environ. Change 23 (5) (2013) 1327-1338.

[8] P. Bubeck, J.C. Aerts, H. de Moel, H. Kreibich, Preface: Flood-risk analysis and integrated management, Nat. Hazards Earth Syst. Sci. 16 (4) (2016) 1005-1010.

[9] K. Burningham, J. Fielding, D. Thrush, 'It'll never happen to me': understanding public awareness of local flood risk, Disasters 32 (2) (2008) 216-238.

[10] Cumbria County Council, Carlisle flood investigation report. Flood event 5-6th December 2015, 2017. URL: https://www.cumbria.gov.uk/elibrary/Content/Inter net/544/3887/6729/6733/42811155021.pdf?timestamp=43718182615 Last accessed: 10 September 2019 .

[11] L. Cumiskey, S. Priest, N. Valchev, C. Viavattene, S. Costas, J. Clarke, A framework to include the (inter) dependencies of Disaster Risk Reduction measures in coastal risk assessment, Coast. Eng. 134 (2018) 81-92.

[12] Department for Communities and Local Government (DCLG)/ Department for Environment Food and Rural Affairs (Defra), Property Level Flood Resilience Local Authority Guidance, Crown copyright: London, 2016 https://www.bitc.org.uk/site s/default/files/berg_-_property_level_flood_resilience_local_authority_guidance.pdf (Accessed 26.07.18).

[13] Defra, Consultation on policy options for promoting property-level flood protection and resilience, 2008.

[14] Defra, The property flood resilience action plan: An action plan to enable better uptake of resilience measures for properties at high flood risk, 2016. URL: https: / /www.bre.co.uk/page.jsp?id=3804 (last accessed 7 March 2019).

[15] Defra, Supporting the uptake of low cost resilience for properties at risk of flooding: Final report (FD2682), 2017a. URL: http://eprints.uwe.ac.uk/32994/1/ 14087 FD2682 Supporting the uptake of low cost resilience FINAL to be published.pdf (last accessed 13 June 2019).

[16] Defra, Defra property level flood resilience roundtable. 2017b end-of-year 1 report, 2017b. URL: https://www.floodguidance.co.uk/wp-content/uploads/2018/05/20 17-PFR-End-of-Year-Report.pdf.

[17] G. Di Baldassarre, A. Viglione, G. Carr, L. Kuil, K. Yan, L. Brandimarte, G. Blöschl, Debates-Perspectives on socio-hydrology: Capturing feedbacks between physical and social processes, Water Resour. Res. 51 (6) (2015) 4770-4781.

[18] G. Everett, J. Lamond, Household behaviour in installing property-level flood adaptations: a literature review, WIT Trans. Ecol. Environ. 179 (2013) 511-522.

[19] T. Grothmann, F. Reusswig, People at risk of flooding: why some residents take precautionary action while others do not, Nat. Hazards 38 (1-2) (2006) 101-120.

[20] J. Handmer, Y. Honda, Z.W. Kundzewicz, N. Arnell, G. Benito, J. Hatfield, K. Takahashi, Changes in impacts of climate extremes: human systems and ecosystems, in: Managing the risks of extreme events and disasters to advance climate change adaptation special report of the intergovernmental panel on climate change, Intergovernmental Panel on Climate Change, 2012, pp. 231-290.

[21] S. Hanger, J. Linnerooth-Bayer, S. Surminski, C. Nenciu-Posner, A. Lorant R. Ionescu, A. Patt, Insurance, public assistance, and household flood risk reduction: A comparative study of Austria, England, and Romania, Risk Anal. 38 (4) (2018) 680-693.

[22] Harries, Review of the Pilot Flood Protection Grant Scheme in a Recently Flooded Area, 2009.

[23] N. Hazarika, T. Tayeng, A.K. Das, Living in troubled waters: stakeholders' perception, susceptibility and adaptations to flooding in the Upper Brahmaputra plain, Nat. Hazards 83 (2) (2016) 1157-1176.

[24] D.L. Hegger, P.P. Driessen, M.A. Wiering, H.F. Van Rijswick, P. Kundzewicz, A. Matczak, C. Larrue, Toward more flood resilience: Is a diversification of flood risk management strategies the way forward? Ecol. Soc. 21 (4) (2016) 52.

[25] D. Henstra, J. Thistlethwaite, C. Brown, D. Scott, Flood risk management and shared responsibility: exploring Canadian public attitudes and expectations, J. Flood Risk Manage. 12 (1) (2019), e12346.

[26] P.G.M.B. Hudson, W.J.W. Botzen, H. Kreibich, P. Bubeck, J.C.J.H. Aerts, Evaluating the effectiveness of flood damage mitigation measures by the application of propensity score matching, Nat. Hazards Earth Syst. Sci. 14 (7) (2014) 1731-1747.

[27] P. Hudson, W.J.W. Botzen, L. Feyen, J.C.J.H. Aerts, Incentivising flood risk adaptation through risk based insurance premiums: trade-offs between affordability and risk reduction, Ecol. Econ. 125 (2016) 1-13.

[28] P. Hudson, W.J. Wouter Botzen, J. Czajkowski, H. Kreibich, Moral hazard in natural disaster insurance markets: empirical evidence from Germany and the United States, Land Econ. 93(2) (2017) 179-208. https://doi.org/10.3368/le 93.2.179.

[29] IPCC, Managing the risks of extreme events and disasters to advance climate change adaptation: special report of the intergovernmental panel on climate change. Cambridge University Press.management strategies the way forward? 2012.

[30] C.L. Johnson, S.J. Priest, Flood risk management in England: a changing landscape of risk responsibility? Int. J. Water Resour. Dev. 24 (4) (2008) 513-525.

[31] B. Jongman, H.C. Winsemius, J.C. Aerts, E.C. de Perez, M.K. van Aalst, W. Kron, P. J. Ward, Declining vulnerability to river floods and the global benefits of adaptation, Proc. Natl. Acad. Sci. 112 (18) (2015) E2271-E2280. 
[32] R. Joseph, D. Proverbs, J. Lamond, Homeowners' perception of the benefits of property level flood risk adaptation (PLFRA) measures: The case of the summer 2007 event in England, Int. J. Saf. Security Eng. 5 (3) (2015) 251-265.

[33] F. Klijn, H. Kreibich, H. De Moel, E. Penning-Rowsell, Adaptive flood risk management planning based on a comprehensive flood risk conceptualisation, Mitig. Adapt. Strat. Glob. Change 20 (6) (2015) 845-864.

[34] H. Kreibich, A.H. Thieken, T. Petrow, M. Müller, B. Merz, Flood loss reduction of private households due to building precautionary measures-lessons learned from the Elbe flood in August 2002, Nat. Hazards Earth Syst. Sci. 5 (1) (2005) 117-126.

[35] H. Kreibich, A.H. Thieken, Coping with floods in the city of Dresden, Germany, Nat. Hazards 51 (3) (2009) 423.

[36] H. Kreibich, I. Seifert, B. Merz, A.H. Thieken, Development of FLEMOcs-a new model for the estimation of flood losses in the commercial sector, Hydrol. Sci. J.-J. Sci. Hydrol. 55 (8) (2010) 1302-1314.

[37] H. Kreibich, S. Christenberger, R. Schwarze, Economic motivation of households to undertake private precautionary measures against floods, Nat. Hazards Earth Syst. Sci. 11 (2) (2011) 309-321.

[38] H. Kreibich, P. Bubeck, M. Van Vliet, H. De Moel, A review of damage-reducing measures to manage fluvial flood risks in a changing climate, Mitig. Adapt. Strat. Glob. Change 20 (6) (2015) 967-989.

[39] H. Kreibich, V. Blauhut, J.C. Aerts, L.M. Bouwer, H.A. Van Lanen, A. Mejia, A. F. Van Loon, How to improve attribution of changes in drought and flood impacts, Hydrol. Sci. J. 64 (1) (2019) 1-18.

[40] H. Kunreuther, M. Useem, Learning from catastrophes: strategies for reaction and response, Pearson Prentice Hall, 2009.

[41] J. Ludy, G.M. Kondolf, Flood risk perception in lands "protected" by 100-year levees, Nat. Hazards 61 (2) (2012) 829-842.

[42] I.M. Martin, H. Bender, C. Raish, What motivates individuals to protect themselves from risks: the case of wildland fires, Risk Anal. 27 (4) (2007), https://doi.org/ 10.1111/j.1539-6924.2007.00930.x.

[43] R. Mason, Government raised bar for funding of flood defence schemes. The Guardian, 2014 Retrieved from https://www.theguardian.com/environment/201 4/feb/11/government-funding-flood-defence-schemes.

[44] R. Mechler, L.M. Bouwer, Understanding trends and projections of disaster losses and climate change: is vulnerability the missing link? Clim. Change 133 (1) (2015) 23-35.

[45] B. Merz, J. Hall, M. Disse, A. Schumann, Fluvial flood risk management in a changing world, Nat. Hazards Earth Syst. Sci. 10 (3) (2010) 509-527.

[46] A.D. Metin, N.V. Dung, K. Schröter, B. Guse, H. Apel, H. Kreibich, B. Merz, How do changes along the risk chain affect flood risk? Nat. Hazards Earth Syst. Sci. 18 (11) (2018).

[47] R. Miceli, I. Sotgiu, M. Settanni, Disaster preparedness and perception of flood risk: A study in an alpine valley in Italy, J. Environ. Psychol. 28 (2) (2008) 164-173.

[48] E. Neumayer, F. Barthel, Normalizing economic loss from natural disasters: a global analysis, Global Environ. Change 21 (1) (2011) 13-24.

[49] D. Osberghaus, The determinants of private flood mitigation measures in Germany-Evidence from a nationwide survey, Ecol. Econ. 110 (2015) 36-50.

[50] S. Owusu, G. Wright, S. Arthur, Public attitudes towards flooding and propertylevel flood protection measures, Nat. Hazards 77 (3) (2015) 1963-1978.
[51] E.C. Penning-Rowsell, S.J. Priest, Sharing the burden of increasing flood risk: who pays for flood insurance and flood risk management in the United Kingdom, Mitig. Adapt. Strat. Glob. Change 20 (6) (2015) 991-1009.

[52] J.K. Poussin, W.W. Botzen, J.C. Aerts, Factors of influence on flood damage mitigation behaviour by households, Environ. Sci. Policy 40 (2014) 69-77.

[53] J.K. Poussin, W.W. Botzen, J.C. Aerts, Effectiveness of flood damage mitigation measures: empirical evidence from French flood disasters, Global Environ. Change 31 (2015) 74-84.

[54] R. Raaijmakers, J. Krywkow, A. van der Veen, Flood risk perceptions and spatial multi-criteria analysis: an exploratory research for hazard mitigation, Nat. Hazards 46 (3) (2008) 307-322.

[55] M. Rolfsen, Das neue wasserhaushaltsgesetz, Natur und Recht 31 (11) (2009) 765.

[56] N. Sairam, K. Schröter, S. Lüdtke, B. Merz, H. Kreibich, Quantifying flood vulnerability reduction via private precaution, Earth's Future (2019).

[57] A. Scolobig, B. De Marchi, M. Borga, The missing link between flood risk awareness and preparedness: findings from case studies in an Alpine Region, Nat. Hazards 63 (2) (2012) 499-520.

[58] S. Seebauer, P. Babcicky, The sources of belief in personal capability: antecedents of self-efficacy in private adaptation to flood risk, Risk Anal. (2020).

[59] State of Queensland, Flood Resilient Building Guidance for Queensland Homes. A joint initiative of the Queensland Government, Brisbane City Council, Ipswich City Council, Lockyer Valley Regional Council, Somerset Regional Council and Seqwater, 2019. URL: https://www.qra.qld.gov.au/sites/default/files/2019-02/ Flood\%20Resilience\%20Building\%20Guidance $\% 20$ for\%20Queensland $\% 20$ Homes $\% 20 \% 28$ February\%202019\%29.pdf.

[60] S. Surminski, J. Eldridge, Flood insurance in England-an assessment of the current and newly proposed insurance scheme in the context of rising flood risk, J. Flood Risk Manage. 10 (4) (2017) 415-435.

[61] S. Surminski, A.H. Thieken, Promoting flood risk reduction: the role of insurance in Germany and England, Earth's Fut. 5 (10) (2017) 979-1001.

[62] C. Suykens, S.J. Priest, V. Doorn-Hoekveld, J. Willemijn, T. Thuillier, M. Van Rijswick, Dealing with flood damages: will prevention, mitigation and ex-post compensation provide for a resilient triangle? Ecol. Soc. 21 (4) (2016).

[63] N. Thurston, B. Finlinson, R. Breakspear, N. Williams, J. Shaw, J. Chatterton, Developing the Evidence Base for Flood Resistance and Resilience, Joint Defra/EA, 2008.

[64] E. Verrucci, G. Perez-Fuentes, T. Rossetto, L. Bisby, M. Haklay, D. Rush, P. Rickles, G. Fagg, H. Joffe, Digital engagement methods for earthquake and fire preparedness: a review, Nat. Hazards 83 (2016) 1583-1604, DOI 10.1007/s11069016-2378-x 2016.

[65] H. Visser, A.C. Petersen, W. Ligtvoet, On the relation between weather-related disaster impacts, vulnerability and climate change, Clim. Change 125 (3-4) (2014) $461-477$.

[66] G. Wachinger, O. Renn, C. Begg, C. Kuhlicke, The risk perception paradox-implications for governance and communication of natural hazards, Risk Anal. 33 (6) (2013) 1049-1065.

[67] Zürich, Post Event Review Capability Report: UK 2015 Flooding in Cumbria after Storm Desmond, 2015. 